\title{
1 Change detection of cotton root rot infection over 10-year \\ 2 intervals using airborne multispectral imagery
}

3

4 Chenghai Yang ${ }^{a, *}$, Gary N. Odvody $^{b}$, J. Alex Thomasson ${ }^{c}$, Thomas Isakeit ${ }^{d}$, Robert L. Nichols ${ }^{e}$ 5

6 a USDA-ARS Southern Plains Agricultural Research Center, Aerial Application Technology

7 Research Unit, 3103 F and B Road, College Station, TX 77845, USA

$8{ }^{\mathrm{b}}$ Texas AgriLife Research and Extension Center, 10345 State HWY 44, Corpus Christi, TX 9 78406, USA

$10{ }^{\mathrm{c}}$ Department of Biological and Agricultural Engineering, Texas A\&M University, College Station, 11 TX 77843, USA

12 d Department of Plant Pathology and Microbiology, Texas A\&M University, College Station, TX 1377843, USA

14 e Cotton Incorporated, 6399 Weston Parkway, Cary, NC 27513, USA

16 * Corresponding author. Tel: 1-979-260-9530

17 E-mail address: chenghai.yang@ars.usda.gov (C. Yang).

\section{ABSTRACT}

20 Cotton root rot is a very serious and destructive disease of cotton grown in the southwestern

21 United States. Accurate information regarding its spatial and temporal distribution within fields is

22 important for effective management of the disease. The objectives of this study were to examine

23 the consistency and variation of cotton root rot infections within cotton fields over 10-year

24 intervals using airborne multispectral imagery and to assess the feasibility to use historical

25 imagery to create prescription maps for site-specific management of the disease. Airborne 
26 multispectral images collected from a 102-ha cotton field in 2001 and 2011 and from a 97-ha

27 field in 2002 and 2012 in south Texas were used in this study. The images were rectified and

28 resampled to the same pixel size between the two years for each field. The normalized

29 difference vegetation index (NDVI) images were generated and unsupervised classification was

30 then used to classify the NDVI images into root rot-infected and non-infected zones. Change

31 detection analysis was performed to detect the consistency and change in root rot infection

32 between the two growing seasons for each field. Results indicate that the spatial patterns of the

33 disease were similar between the two seasons, though variations existed for each field. To

34 account for the potential expansion and temporal variation of the disease, buffer zones around

35 the infected areas were created. The buffered maps between the two years agreed well. The

36 results from this study demonstrate that classification maps derived from historical images in

37 conjunction with appropriate buffer zones can be used as prescription maps for site-specific

38 fungicide application to control cotton root rot.

40 Keywords. Airborne multispectral imagery, buffer zone, change detection, cotton root rot, image 41 classification, NDVI.

42

\section{1. Introduction}

44

45 Cotton root rot, caused by the fungus Phymatotrichopsis omnivora, is a destructive cotton 46 disease occurring throughout the southwestern United States and northern Mexico (Percy, 47 1983). Cotton (Gossypium hirsutum L.) is an economically important crop that is highly 48 susceptible to this disease. The symptoms usually begin during extensive vegetative growth, 49 are more visible during flowering and fruit development, and continue through the growing 50 season (Smith et al., 1962). Infected plants wilt and quickly die with the leaves attached to the 51 plants. The fungus usually spreads more during rainy years as moisture favors all aspects of the 
52 disease cycle. Plants infected earlier in the growing season will die before bearing fruit, whereas

53 infection occurring at later growth stages will reduce cotton yield and lower lint quality (Ezekiel 54 and Taubenhaus, 1934; Yang et al., 2005).

55 Cotton root rot has plagued the cotton industry for more than 100 years (Pammel, 1988;

56 Uppalapati et al., 2010). Cultural practices such as deep plowing, organic amendments, late 57 planting, and rotation with monocotyledonous crops have been used to reduce the occurrence 58 and severity of the disease (Smith et al., 1962; Rush and Lyda, 1984). Some fumigants and 59 fungicides applied to root rot-infected areas reduced the incidence of the disease, but they were 60 not consistently effective and economical for long-term control (Lyda and Burnett, 1970; 61 Whitson and Hine, 1986). Despite decades of research efforts, effective practices for control of 62 this disease were lacking until TOPGUARD ${ }^{\circledR}$ Fungicide, a commercial formulation of flutriafol 63 from Cheminova, Inc. (Wayne, NJ), showed considerable promise for suppressing this disease 64 in field studies (Isakeit et al., 2009, 2012).

65 TOPGUARD (flutriafol) was used effectively in Texas from 2012 to 2014 to control cotton 66 root rot under Section 18 emergency exemptions granted by the U.S. Environmental Protection 67 Agency (EPA). As a result, growers achieved lower cotton root rot incidence, higher yields, and 68 better fiber quality (Drake et al., 2013). In early 2015, TOPGUARD ${ }^{\circledR}$ TERRA Fungicide, a new 69 and more concentrated formulation of flutriafol developed specifically for this market, was 70 registered by the EPA. It provides the same level of cotton root rot control as TOPGUARD. 71 Growers generally treat their fields uniformly even though they are aware that only portions of 72 their fields are infected. There are probably two main reasons for the uniform treatment. One is 73 that growers want to make sure all existing and potential new infections are treated since they 74 are not sure if the infection patterns will expand from year to year. The other reason is that site75 specific application equipment and the capacity to create prescription maps are not readily 76 available for their use. Since only portions of the field are infected, it may not be appropriate to 77 treat the whole field. Therefore, it is necessary to define the infected areas within the field so 
78 that variable rate technology can be used to apply the fungicide only to the infected areas for 79 more effective and economical control.

80 Remote sensing has long been used as a useful tool for mapping cotton root rot in cotton

81 fields (Taubenhaus et al., 1929; Nixon et al., 1975, 1987). Remote sensing is perhaps the only

82 practical means for accurately and effectively mapping this disease because of large numbers

83 of infected areas and their irregular shapes within cotton fields. In our previous studies, airborne

84 imagery has been successfully used to map the extent of cotton root rot infections near the end

85 of the growing season when cotton root rot is fully pronounced for the season (Yang et al.,

86 2005) and to monitor the progression of the infections within cotton fields during a growing

87 season (Yang et al., 2014). In these studies, ISODATA (Iterative Self-Organizing Data Analysis)

88 unsupervised classification applied to multispectral imagery has been used to identify root rot-

89 infected areas. With this method, the optimal number of spectral classes is determined based

90 on the average transformed divergence for each classification map. The spectral classes are

91 then grouped into root rot-infected and non-infected zones.

92 More recently, Yang et al. (2015) evaluated and compared two unsupervised classification

93 techniques (ISODATA applied to multispectral imagery and to NDVI) and six supervised

94 classification techniques (minimum distance, Mahalanobis distance, maximum likelihood,

95 spectral angle mapper (SAM), neural net, and support vector machine (SVM)) for mapping and

96 detecting cotton root rot from airborne multispectral imagery. Although all eight methods appear

97 to be equally effective and accurate for detection of cotton root rot, the NDVI-based

98 classification can be easily implemented without the need for complex image processing

99 capability. Therefore, it has been recommended as one of the simple and accurate classification

100 methods to map cotton root rot and develop prescription maps for effective and economical

101 control of this disease.

102 The objectives of this study were to: (1) examine the consistency and variation of cotton root 103 rot infection within two cotton fields based on airborne multispectral imagery taken over 10-year 
104 intervals; and (2) assess the feasibility to use historical imagery to create prescription maps for 105 site-specific management of the disease. This information is important not only for a better 106 understanding of the progression of the disease over a relatively long period of time, but also for 107 the formulation of site-specific strategies for effective control of the disease.

108

109 2. Materials and methods

1112.1 Study area

113 This study was conducted in two center-pivot irrigated fields near Edroy, Texas over 10-year 114 intervals. Field 1 was a 102 -ha circular field with center coordinates of $\left(27^{\circ} 58^{\prime} 19^{\prime \prime} \mathrm{N}\right.$, $11597^{\circ} 42^{\prime} 29^{\prime \prime}$ ) and Field 2 was a 97-ha semicircular field with center coordinates of $\left(28^{\circ}\right.$ $\left.1161 ' 10.86 " \mathrm{~N}, 97^{\circ} 42^{\prime} 49.22 " \mathrm{~W}\right)$. Both fields had a history of cotton root rot. Cotton and grain 117 sorghum had been cropped alternately in the fields. Cotton was planted to Field 1 in 2001 and 1182011 and to Field 2 in 2002 and 2012.

$120 \quad 2.2$ Image acquisition

122 Three different imaging systems were used to acquire images from the two fields in four 123 different years shortly before harvest when root rot was fully expressed for the respective 124 season. A three-camera imaging system described by Escobar et al. (1997) was used to 125 acquire images from Field 1 on 9 July 2001 and from Field 2 on 19 July 2002. The imaging 126 system consisted of three digital charge coupled device (CCD) cameras and a computer 127 equipped with three image digitizing boards that had the capability of obtaining 8-bit images with $1281024 \times 1024$ pixels. The three cameras were filtered for spectral observations in the green 
129 (555-565 nm), red (625-635 nm), and near-infrared (NIR, 845-857 nm) wavelength intervals, 130 respectively.

131 A four-camera imaging system described by Yang (2012) was used to acquire images from

132 Field 1 on 7 July 2011. The system consisted of four high-resolution CCD digital cameras and a 133 ruggedized PC equipped with frame grabbers and image acquisition software. The four cameras 134 were filtered to capture 12-bit images with $2048 \times 2048$ pixels in four spectral bands: blue 135 (430-470 nm), green (530-570 nm), red (630-670 nm), and NIR (810-850 nm), respectively. A 136 two-camera imaging system described by Yang et al. (2014) was used to take images from 137 Field 2 on 25 July 2012. The system consisted of two consumer-grade digital cameras with a $1385616 \times 3744$ pixel array. One camera captured normal RGB color images, while the other 139 camera was equipped with a 720-nm long-pass filter to obtain NIR images.

140 A Cessna 206 single-engine aircraft was used to acquire imagery from the two fields in each

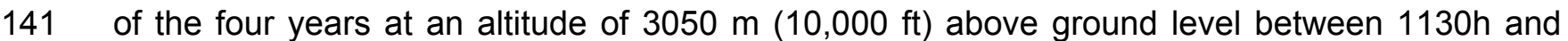
142 1530h local time under sunny conditions. Images from the three-camera and four-camera 143 systems were saved to the respective on-board computers as three-band and four-band Tiff 144 files, respectively, while images from the two-camera system were stored in two separate 145 CompactFlash (CF) cards in both 14-bit RAW and 8-bit JPEG files. The ground pixel size 146 achieved was $1.3 \mathrm{~m}$ in 2001 and 2002 and $1.0 \mathrm{~m}$ in 2011 and 2012.

\subsection{Image processing and classification}

An image-to-image registration procedure based on the first-order polynomial transformation

151 model was used to align the individual band images in the three-band and four-band composite 152 images as well as the RGB and NIR images from the two-camera system. The aligned images 153 were then georeferenced or rectified to the Universal Transverse Mercator (UTM), World 154 Geodetic System 1984 (WGS-84), Zone 14, coordinate system based on a set of ground control 
155 points around each field located with a Trimble GPS Pathfinder ProXRS receiver (Trimble 156 Navigation Limited, Sunnyvale, California). The root mean square errors for rectifying the 157 images using first-order transformation were within $2 \mathrm{~m}$. All images were resampled to $1 \mathrm{~m}$

158 resolution using the nearest neighborhood technique. All procedures for image alignment and 159 rectification were performed using ERDAS Imagine (Intergraph Corporation, Madison, 160 Alabama).

161 The rectified images for the two dates were stacked as one image for each field. A field 162 boundary or an area of interest (AOI) was defined for each field. Normalized difference 163 vegetation index (NDVI) images were created for each field and year combination using the 164 following formula:

$$
N D V I=\frac{N I R-R E D}{N I R+R E D}
$$

166 where NIR and RED stand for the reflectance values for the NIR and red bands, respectively.

167 NDVI values range from -1 to 1 with low positive and even negative values for infected plants 168 and high positive values for healthy plants.

169 The NDVI images were classified into root rot-infected and non-infected zones using 170 ISODATA unsupervised classification (Intergraph Corporation, 2013). The ISODATA method 171 began with two classes and arbitrary class means from the NDVI image statistics. Each pixel 172 was assigned to the class that had a smaller NDVI difference to the pixel. Each time the 173 clustering repeated, the means of the two classes were recalculated and used for the next 174 iteration. The process continued until the number of iterations reached 100 or the percentage of 175 unchanged pixels reached $99.99 \%$ between two iterations. Pixels with lower NDVI values 176 correspond to the root rot-infected zone, while pixels with higher NDVI values belong to the non177 infected zone. 
Change detection analysis was performed on the classification maps to determine the class changes between the two years for each field. Change detection statistics, including common

183 root rot areas in both years and root rot areas only in one of the two years, were calculated.

184 To simulate the potential expansion and temporal variation of the disease, buffer zones 185 around the infected areas were created using Arclnfo GIS (ESRI, Inc., Redlands, California).

186 The classification maps generated in ERDAS Imagine were converted into Arclnfo grids. Then 187 the GRID EXPAND function in Arclnfo was used to create buffer zones of 1-20 m with an 188 increment of $1 \mathrm{~m}$ around the infected areas in each grid. The total area of the original root rot 189 areas and the buffered areas for each of the 20 buffer distances were derived from the buffered 190 grids.

191 To further examine the consistency and change of root rot infection over the 10-year 192 intervals, the original classification map for one year was compared with each of the buffered 193 classification maps for the other year to determine the overlapped areas between the original 194 map and each buffered map.

\section{Results and discussion}

\subsection{Image classification}

Fig. 1 shows the color-infrared (CIR) images acquired in 2001 and 2011 and the 202 showed a reddish-magenta tone, while infected plants had a greenish or cyanish color. The root 203 rot-infected areas can be easily distinguished from the non-infected areas on the CIR images.

204 A visual comparison of the classification maps and their respective CIR images indicates 205 that the two-zone classification maps effectively identify apparent root rot areas within the fields. 
206 The estimated percent root rot areas for the field were $13.6 \%$ in 2001 and $17.8 \%$ in 2011 . The 207 overall spatial patterns of infections between the two years were similar, but the infected area 208 increased in 2011 and there were changes in infection locations.

209 Fig. 2 shows the CIR images acquired in 2002 and 2012 and the corresponding two-zone 210 classification maps for Field 2. Similarly, the two-zone classification maps accurately identify 211 apparent root rot areas within the field. The estimated percent root rot areas for the field were $21211.7 \%$ in 2002 and $8.7 \%$ in 2012 . The overall spatial patterns of infections between the two 213 years were similar, but the infected area decreased in 2012 because some of the infected areas 214 in 2002 were not fully pronounced in 2012. Nevertheless, cotton root rot occurred in the same 215 general areas within the field and there were a few newly-infected areas in 2012. This recurrent 216 pattern of the disease was also found in many other fields (Yang et al., 2012). 

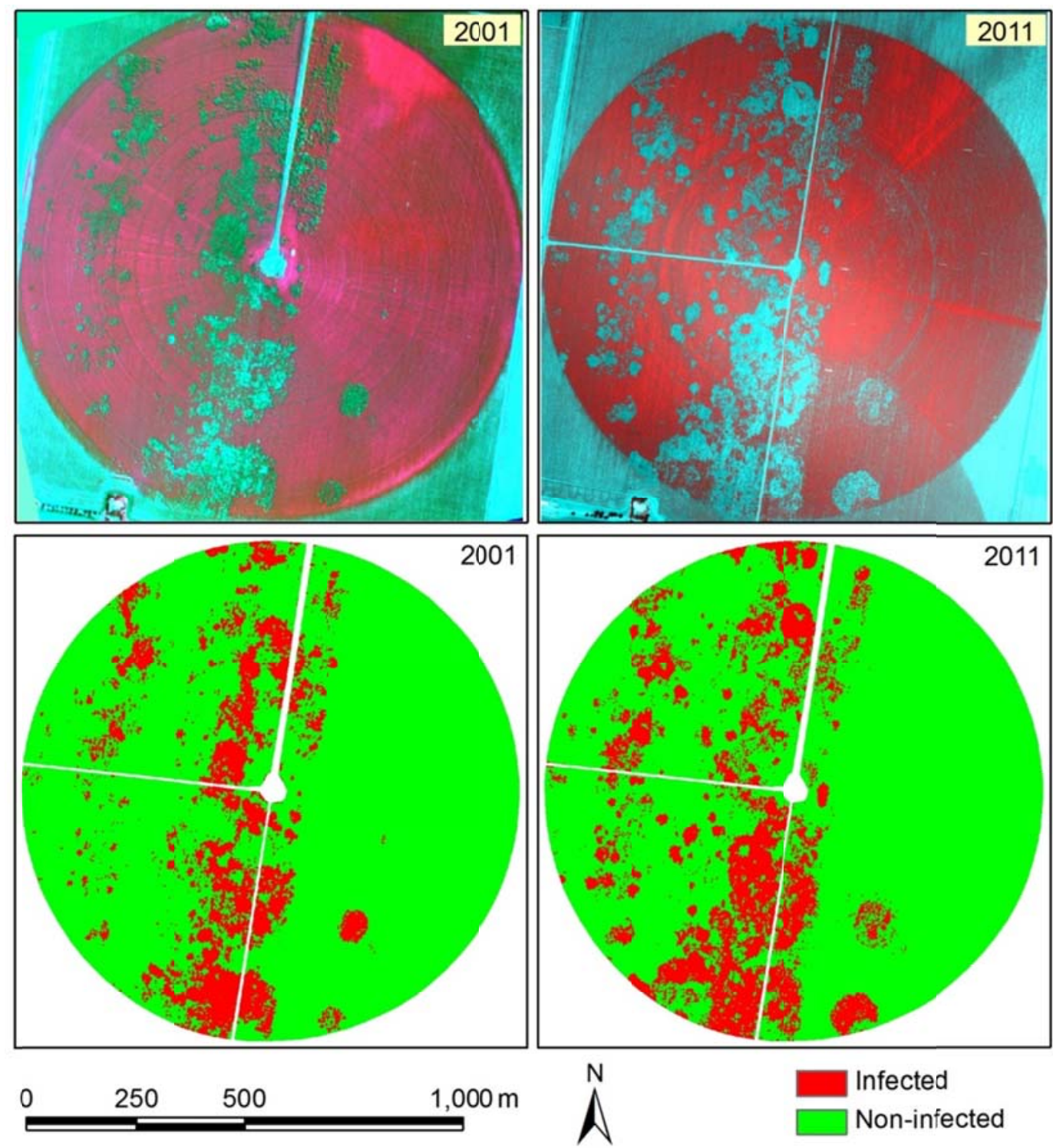

Infected

Non-infected

218 Fig. 1. Airborne color-infrared images (top) and two-zone classification maps (bottom) derived 219 from NDVI images for a 102-ha cotton root rot-infected field (Field 1) near Edroy, Texas in 2001 220 and 2011. 

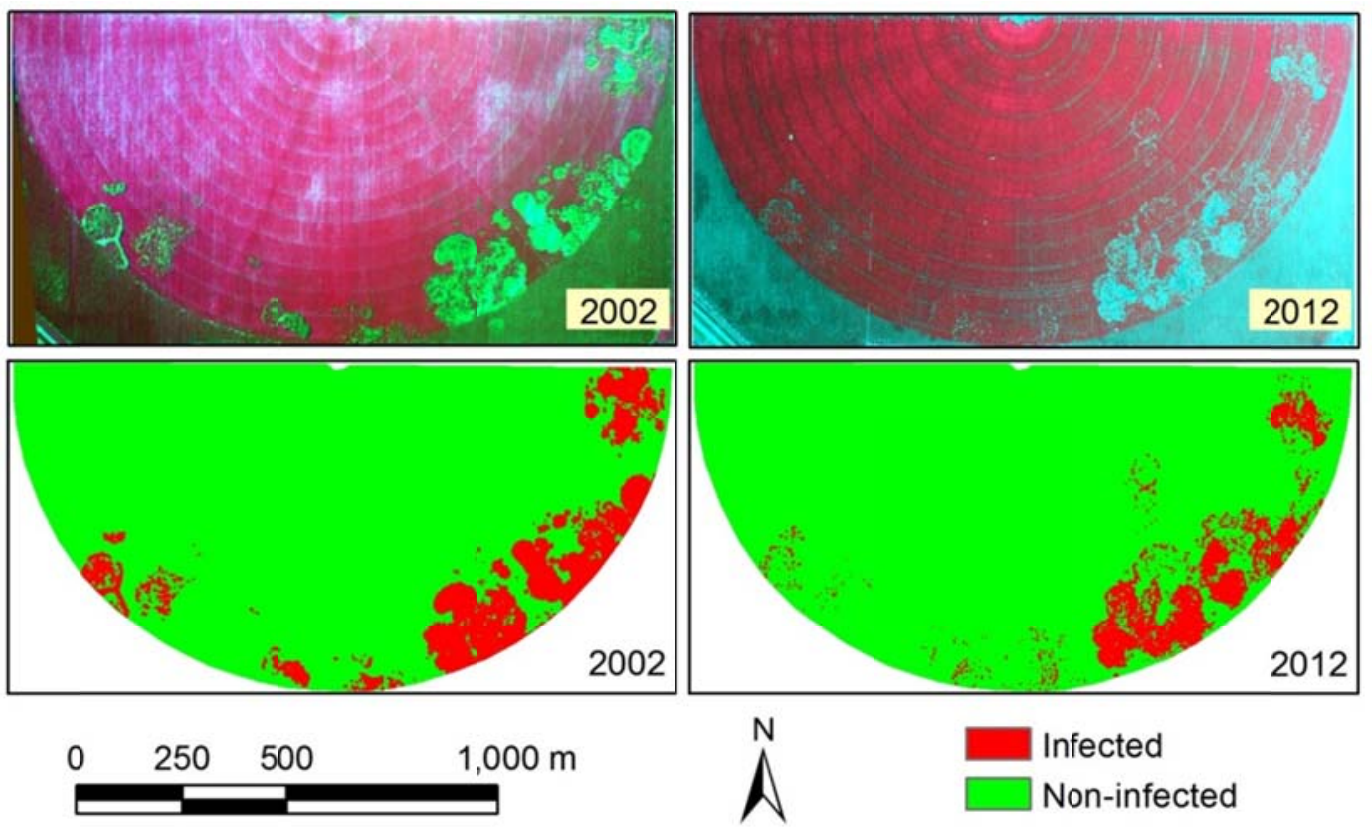

224 Fig. 2. Airborne color-infrared images (top) and two-zone classification maps (bottom) derived 225 from NDVI images for a 97-ha cotton root rot-infected field (Field 2) near Edroy, Texas in 2002 226 and 2012.

\subsection{Change detection}

Fig. 3 shows the overlaid map (left) of the two classification maps in 2001 and 2011 for Field

231 1. The red shows the infected areas in both years, the blue shows the infected areas only in 232 2001, and the yellow depicts the infected areas only in 2011. Change detection analysis showed

233 that $7.8 \%$ of the field was infected in both years, while $5.8 \%$ of the field was infected only in 2342001 and $10.0 \%$ only in 2011 (Table 1). Thus, the total infected area in either 2001 or 2011 was $23523.6 \%(7.8 \%+5.8 \%+10.0 \%)$ as shown by the merged two-zone map in Fig. 3 (right). 


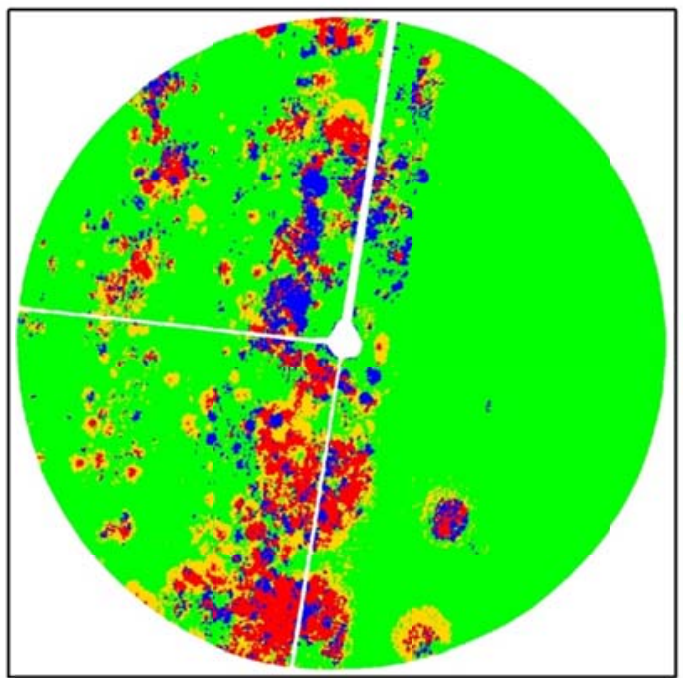

Infected in both years

Infected only in 2001

$\square$ Infected only in 2011

Non-infected in both years

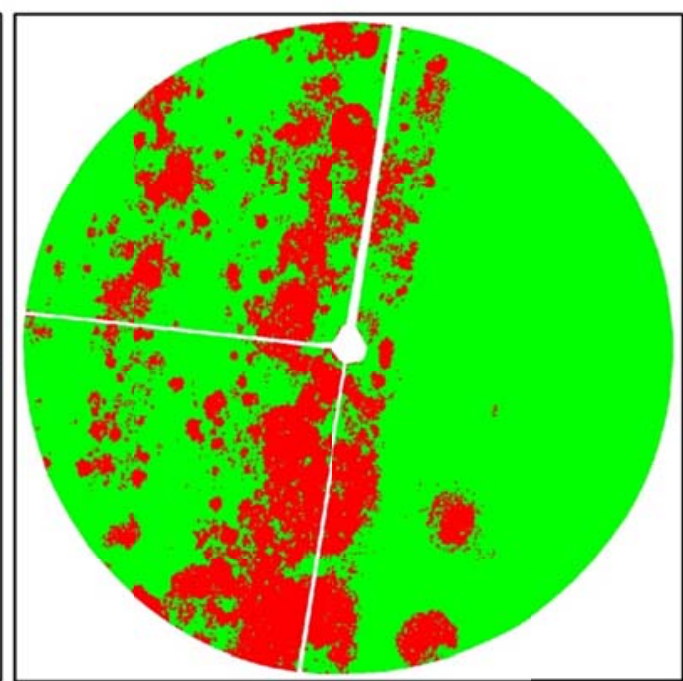

Infected in either year

Non-infected

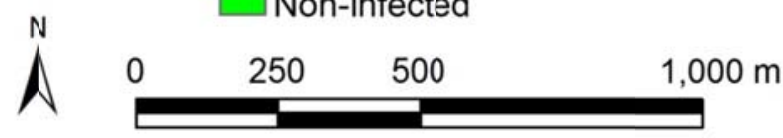

238 Fig. 3. Overlaid four-zone classification map between 2001 and 2011 (left) and merged two-

239 zone classification map for Field 1.

\section{Table 1}

242 Change detection statistics in terms of percent area (\%) between two classification maps from 243 airborne imagery acquired in 2001 and 2011 for Field 1.

$$
\text { Initial state (2001) }
$$

\begin{tabular}{ccccc}
\hline & Class & Infected & Non-infected & Row total \\
\hline \multirow{2}{*}{ Final state } & Infected & 7.8 & 10.0 & 17.8 \\
& Non-infected & 5.8 & 76.4 & 82.2 \\
\cline { 2 - 5 } & Column total & 13.6 & 86.4 & \\
& Class change & 4.2 & -4.2 & \\
& & & & \\
\hline
\end{tabular}


245 Fig. 4 shows the overlaid map (left) of the two classification maps in 2002 and 2012 for Field

246 2. Change detection analysis showed that $5.3 \%$ of the field was infected in both years, while

$2476.4 \%$ of the field was infected only in 2002 and $2.8 \%$ only in 2012 (Table 2). Thus, the total 248 infected area in either 2002 or 2012 was $14.5 \%(5.3 \%+6.4 \%+2.8 \%)$ as shown by the merged 249 two-zone map in Fig. 4 (right). The merged two-zone infection maps for both fields can be used 250 as base maps for site-specific fungicide treatment.

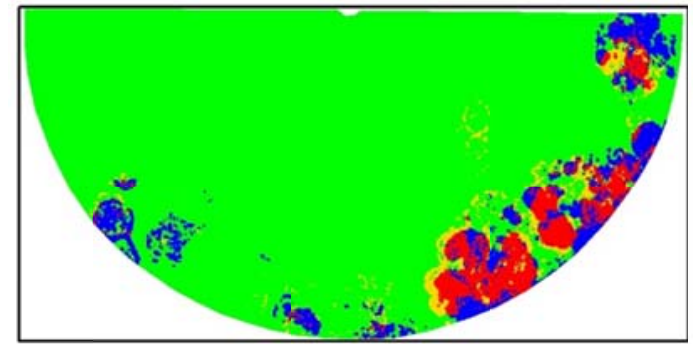

Infected in both years

Infected only in 2002 $\square$ Infected only in 2012

$\square$ Non-infected in both years

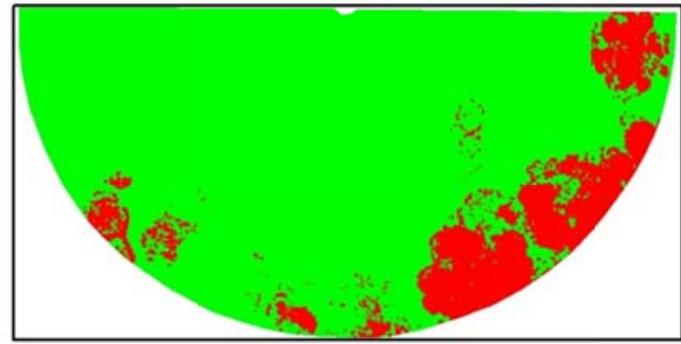

Infected in either year

Non-infected

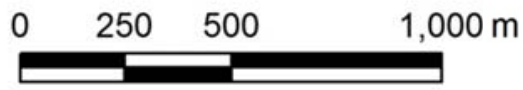

252 Fig. 4. Overlaid four-zone classification map between 2002 and 2012 (left) and merged two253 zone classification map for Field 2.

\section{Table 2}

256 Change detection statistics in terms of percent area (\%) between two classification maps from 257 airborne imagery acquired in 2002 and 2012 for Field 2.

$$
\text { Initial state (2002) }
$$

\begin{tabular}{ccccc}
\hline & Class & Infected & Non-infected & Row total \\
\hline \multirow{2}{*}{ Final state } & Infected & 5.3 & 2.8 & 8.1 \\
& Non-infected & 6.4 & 85.5 & 91.9 \\
\cline { 2 - 5 } & Column total & 11.7 & 88.3 & \\
& Class change & -3.6 & 3.6 & \\
& & & & \\
\hline
\end{tabular}




\subsection{Effect of buffer distance on root rot maps}

Fig. 5 presents the percent root rot areas with buffers of 0-20 $\mathrm{m}$ for the separate years and

the two years combined for Fields 1 and 2. It can be seen clearly that percent area increased with buffer distance, but the increase rate decreased with buffer distance. At smaller buffer distance, percent area increased faster with buffer distance. At larger buffer distance, percent area increased at a slower rate. For example, percent area would have increased to anywhere between 2.2 and 3.8 times if the fungus had expanded by $20 \mathrm{~m}$ for the two fields, compared with the 1.8 to 2.9 times for the first $10 \mathrm{~m}$ buffer. For the second $10 \mathrm{~m}$, the net increase was only 0.4 to 0.9 times of the original areas, much smaller than for the first $10 \mathrm{~m}$. The reason for this difference is partly due to the fact that the original classification maps contained many small polygons and these polygons expanded in all directions and quickly filled the gaps between polygons at smaller buffer distances. As buffer distance increased further, the increase rate

272 tended to reduce. Nevertheless, as buffer distance continues to increase, all the curves in Fig. 5 273 will eventually reach the $100 \%$ maximum.
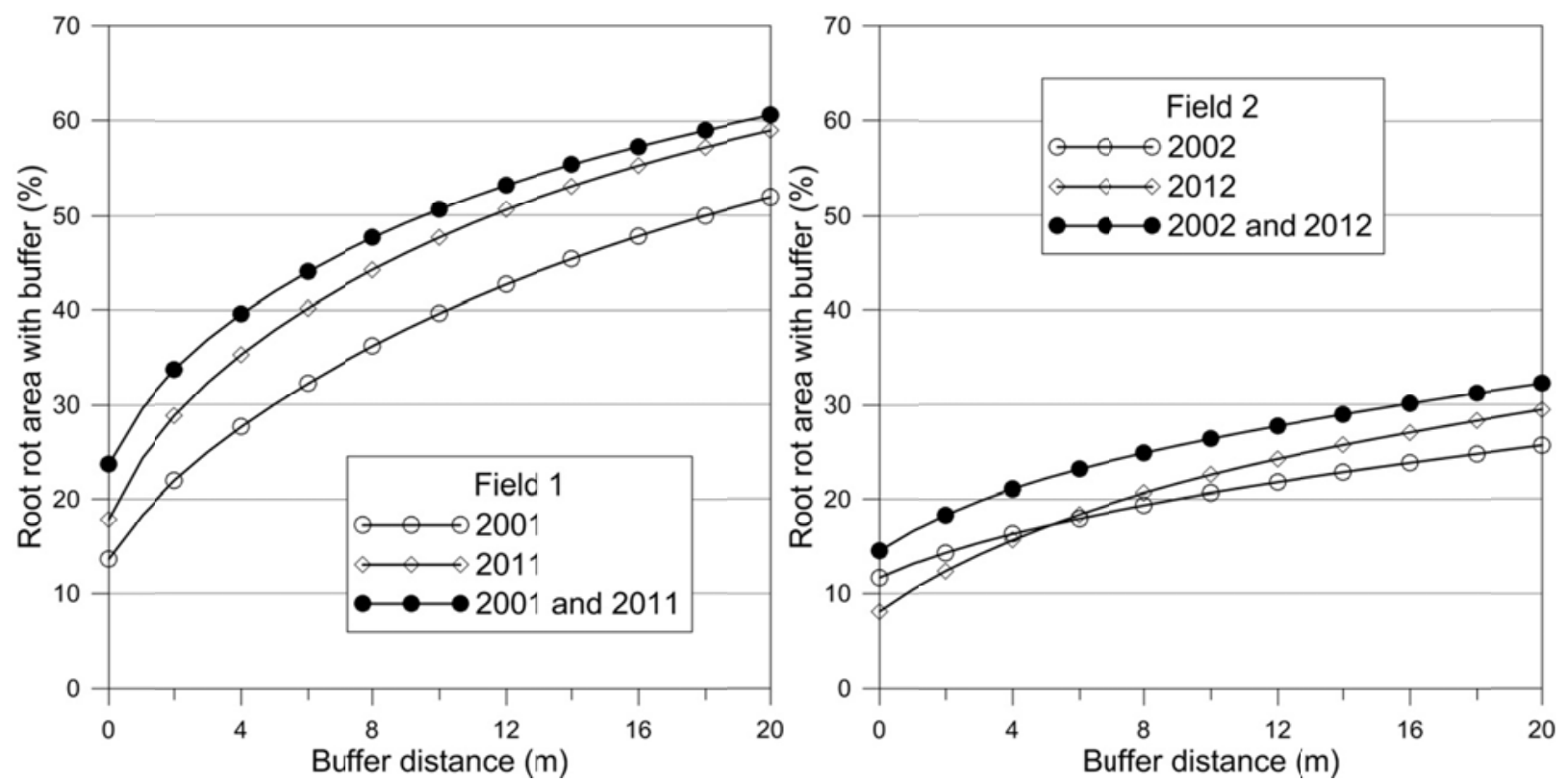
277 Fig. 5. Percent root rot area with buffers of 0-20 m for two separate years and the two years 278 combined for Fields 1 and 2.

Tables 3 and 4 summarize the percent root rot area with buffer zones of $0-10 \mathrm{~m}$ around the 281 infected areas for the separate years and the two years combined for Fields 1 and 2, 282 respectively. For Field 1, the percent root rot area increased from $13.6 \%$ for the 0 -m buffer 283 (original infection) to $39.6 \%$ (almost tripled) for the $10-\mathrm{m}$ buffer in 2001 , and from $17.8 \%$ for the 2840 -m buffer to $47.6 \%$ (2.7 times the original) for the 10-m buffer in 2011 for Field 1. For Field 2, 285 the percent root rot area increased from $11.7 \%$ for the $0-\mathrm{m}$ buffer to $20.6 \%$ (1.8 times) for the $28610-\mathrm{m}$ buffer in 2002, and from $8.1 \%$ for the 0 -m buffer to $22.6 \%$ (2.8 times) for the $10-\mathrm{m}$ buffer in 287 2012. When the classification maps for the two years were merged, the percent root rot area 288 increased from $23.6 \%$ for the 0 -m buffer to $50.6 \%$ (more than doubled) for the $10-\mathrm{m}$ buffer for 289 Field 1, and from 14.5\% for the 0 -m buffer to $26.4 \%$ (1.8 times) for the 10-m buffer for Field 2. 290 Clearly, root rot areas could have increased to anywhere between 1.8 to 2.9 times the original 291 areas if the fungus had expanded by $10 \mathrm{~m}$ for the two fields.

Table 3

294 Root rot area with buffer in percent area (\%) at 11 buffer distances for 2001, 2011 and the two 295 years combined for Field 1.

\begin{tabular}{cccccccccccc}
\hline \multirow{2}{*}{ Year } & \multicolumn{10}{c}{ Buffer distance $(\mathrm{m})$} \\
\cline { 2 - 13 } & 0 & 1 & 2 & 3 & 4 & 5 & 6 & 7 & 8 & 9 & 10 \\
\hline 2001 & 13.6 & 18.3 & 21.9 & 25.0 & 27.6 & 30.0 & 32.2 & 34.3 & 36.2 & 38.0 & 39.6 \\
2011 & 17.8 & 24.4 & 28.8 & 32.3 & 35.3 & 37.9 & 40.2 & 42.3 & 44.2 & 46.0 & 47.6 \\
$2001 \& 2011$ & 23.6 & 29.7 & 33.7 & 36.9 & 39.6 & 41.9 & 44.0 & 45.9 & 47.6 & 49.2 & 50.6
\end{tabular}


299 Root rot area with buffer in percentage (\%) at 11 buffer distances for 2002, 2012 and the two 300 years combined for Field 2.

\begin{tabular}{ccccccccccccc}
\hline \multirow{2}{*}{ Year } & \multicolumn{10}{c}{ Buffer distance (m) } \\
\cline { 2 - 14 } & 0 & 1 & 2 & 3 & 4 & 5 & 6 & 7 & 8 & 9 & 10 \\
\hline 2002 & 11.7 & 13.1 & 14.4 & 15.4 & 16.4 & 17.2 & 18.0 & 18.7 & 19.4 & 20.0 & 20.6 \\
2012 & 8.1 & 10.5 & 12.4 & 14.2 & 15.7 & 17.1 & 18.4 & 19.6 & 20.6 & 21.6 & 22.6 \\
$2002 \& 2012$ & 14.5 & 16.6 & 18.3 & 19.8 & 21.1 & 22.2 & 23.1 & 24.0 & 24.9 & 25.6 & 26.4
\end{tabular}

The expansion rate with buffer distance depends on the spatial distribution and extent of the original root rot infection. It can be seen from Fig. 5 and Tables 3 and 4 that Field 1 had more root rot than Field 2 and that the expansion rate with buffer distance were generally faster for Field 1 than for Field 2. Moreover, the expansion rate with buffer differed for different years for the same field. For example, the expansion rate looked similar for the two years for Field 1, but differed for the two years for Field 2. The expansion rate was much faster for 2012 than for 2002 for Field 2. Although original infection was smaller for 2012 than for 2002, the percent root rot area with a 5-m buffer for 2012 reached that for 2002 .

Figs. 6 and 7 show the two-zone classification maps with a 5-m buffer around infected areas

311 for the two separate years and the two years combined for Fields 1 and 2, respectively. The 312 percent root rot areas with the buffer were $30.0 \%, 37.9 \%$ and $41.9 \%$ (or 2.2, 2.1 and 1.8 times 313 the original infection) for 2001,2011 , and the two years combined for Field 1. For Field 2, the 314 percent root rot areas with the buffer were $17.2 \%, 17.1 \%$ and $22.2 \%$ (or $1.5,2.1$ and 1.5 times 315 the original infection) for 2002, 2012, and the two years combined for Field 2. These maps along 316 with other maps created with different buffer distances can be used for estimation of root rot 317 areas and for site-specific fungicide treatment of cotton root rot. 

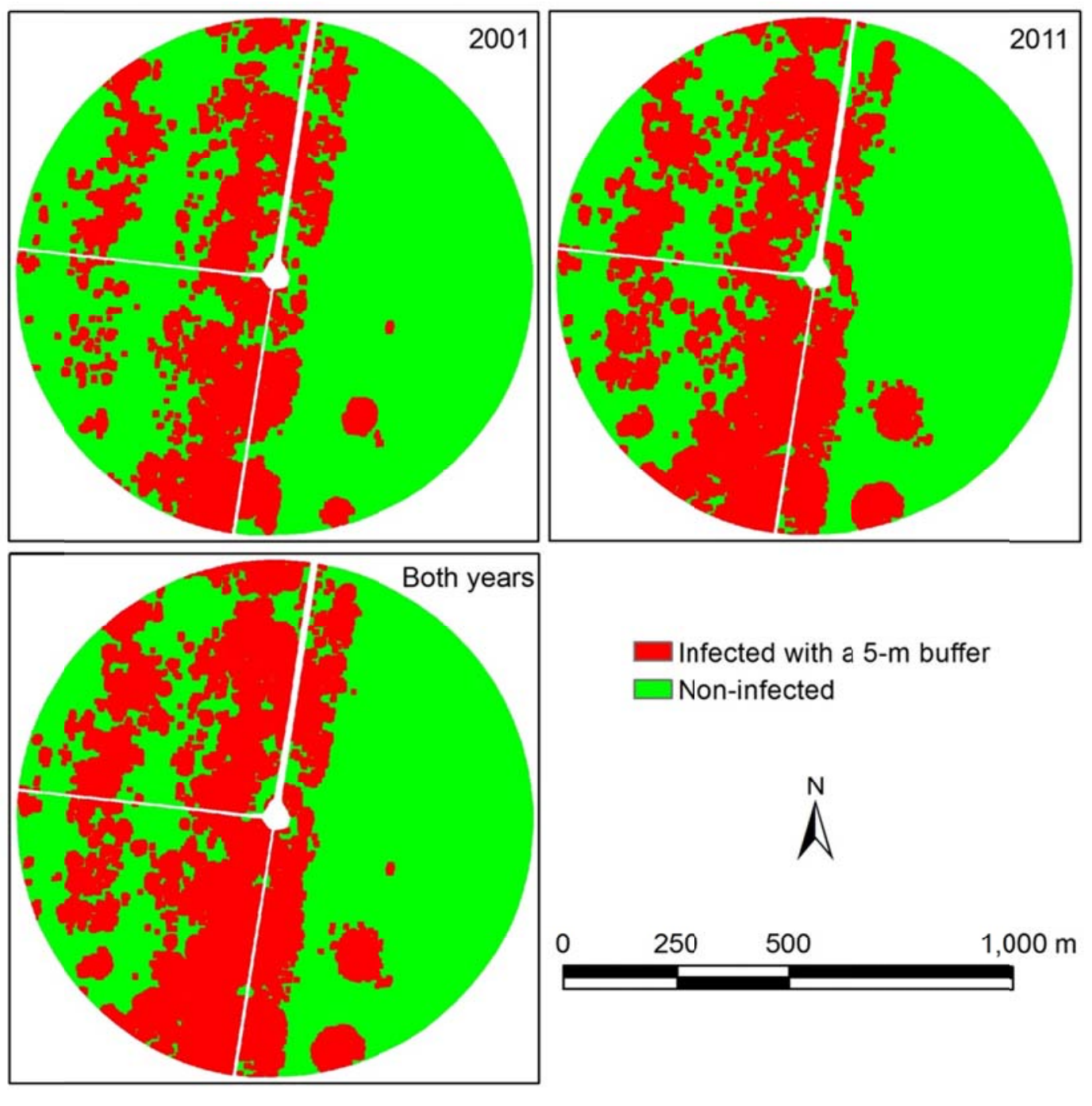

Fig. 6. Classification maps with a 5-m buffer around infected areas for 2001, 2011 and the two

321 years combined for Field 1. 

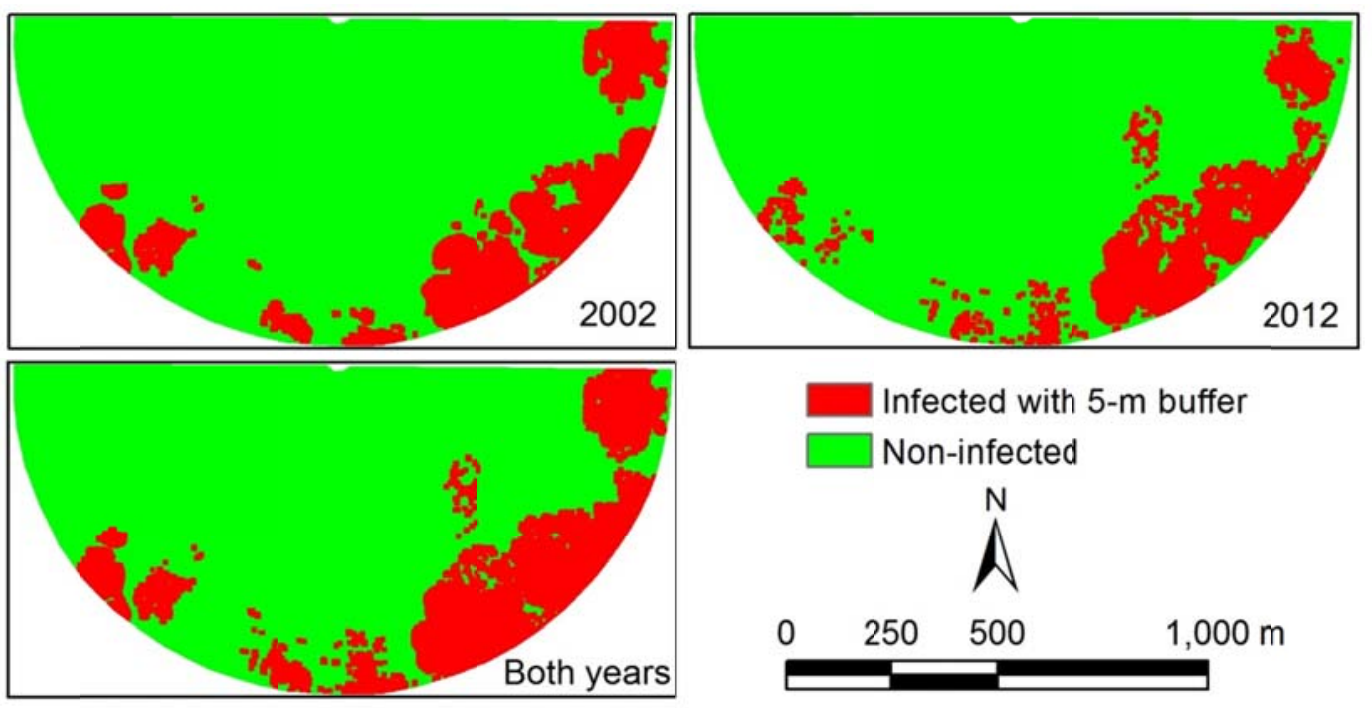

Fig. 7. Classification maps with a 5-m buffer around infected areas for 2002, 2012 and the two years combined for Field 2.

\subsection{Overlapped root rot area between years with buffer distance}

Based on the change detection analysis results, only $7.8 \%$ of the infection out of the $13.6 \%$ in 2001 and the $17.8 \%$ in 2011 occurred simultaneously in both years for Field 1 (Table 1).

332 Similarly, only $5.3 \%$ of the infection out of the $11.7 \%$ in 2002 and the $8.1 \%$ in 2012 occurred in 333 both years for Field 2 (Table 2). In other words, only 57\% (7.8/13.6) of the infection in 2001 and $33444 \%(7.8 / 17.8)$ of the infection in 2011 overlapped for Field 1, and only $45 \%(5.3 / 11.7)$ of the 335 infection in 2002 and 65\% (5.3/8.1) of the infection in 2011 overlapped for Field 2. From the 336 analysis in Section 3.3, by creating a buffer zone around the infected areas, the root rot area 337 with the buffer could increase significantly. It will be interesting to see how much the overlapped 338 root rot area will be between the two years for each field if the root rot area for one year is 339 expanded by a buffer distance.

$340 \quad$ Fig. 8 presents overlapped percent root rot areas between two years when buffer zones of $341 \quad 0-20 \mathrm{~m}$ were created for one year for Fields 1 and 2 . The overlapped percent area increased 
342 with buffer distance asymptotically, approaching the 100\% maximum. For example, overlapped 343 percent areas with a 9-m buffer exceeded $90 \%$ for either year for Field 1, whereas overlapped 344 percent areas with a 12-m buffer exceeded $90 \%$ for either year for Field 2. By increasing the 345 buffer distance further, overlapped percent areas will continue to increase but at a much lower 346 rate. Although larger buffer distance will ensure more potential root rot areas are covered in the 347 prescription map, but the treatment areas will also increase significantly. The optimal buffer 348 distance depends on the particular infection in each field. If images are available only for one 349 season, larger buffer distance can be used; otherwise, merged root rot maps for multiple 350 seasons should be used with smaller buffer distance.
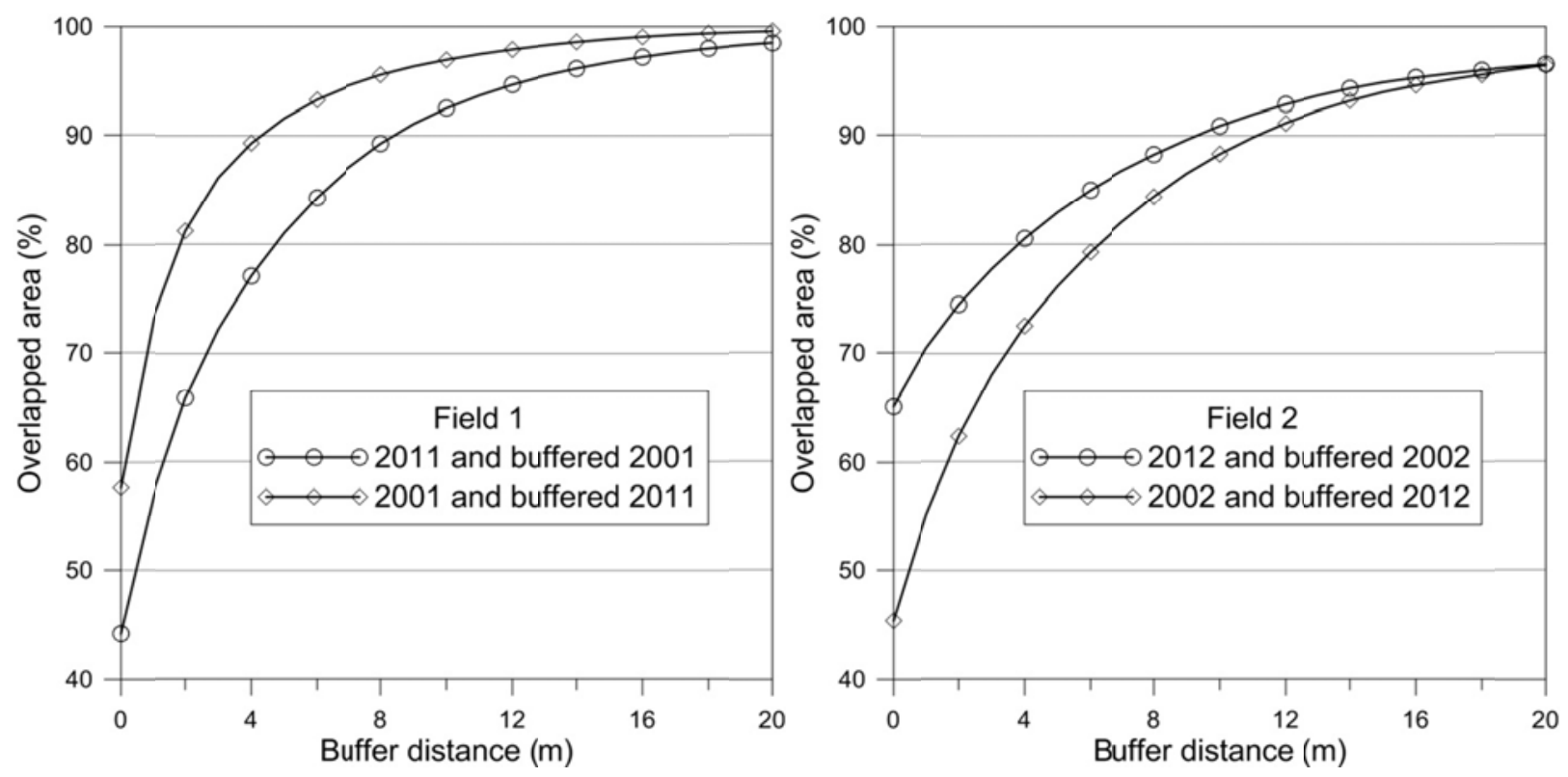

354 Fig. 8. Overlapped percent root rot area between two years if buffer zones of $0-20 \mathrm{~m}$ are 355 created for one year for Fields 1 and 2.

Tables 5 and 6 summarize the overlapped root rot areas between two years when buffer zones of 0-10 m were created for one year at a time for Fields 1 and 2, respectively. When the root rot areas with buffers of $0-10 \mathrm{~m}$ for 2001 were overlaid with the original root rot map for 

2011 for Field 1, the overlapped area over the original infection for 2011 increased from 44.1\%

361 for the $0-\mathrm{m}$ buffer to $92.5 \%$ for the $10-\mathrm{m}$ buffer. When the root rot areas with buffers of $0-10 \mathrm{~m}$ 362 for 2011 were overlaid with the original root rot map for 2001 for Field 1, the overlapped area 363 over the original infection for 2001 increased from $57.7 \%$ for the 0 -m buffer to $97.0 \%$ for the 10 $364 \mathrm{~m}$ buffer. Similarly, the overlapped area over the original infection for 2012 increased from $36565.1 \%$ to $90.9 \%$ with buffers of $0-10 \mathrm{~m}$ applied to the original root rot maps for 2002 , and the 366 overlapped area over the original infection for 2002 increased from $45.3 \%$ to $88.3 \%$ with buffers 367 of $0-10 \mathrm{~m}$ applied to the original root rot maps for 2012 for Field 2. Obviously, by applying a 368 buffer distance to the original root rot map in one year, the buffered map will cover most of the 369 original infection in the other year. This result is important if only one year's imagery is available 370 for generating prescription maps.

Table 5

373 Overlapped root rot area in ha and percentage (\%) between two years if buffer zones are 374 created for one year for Field 1.

\begin{tabular}{|c|c|c|c|c|c|c|c|c|c|c|c|c|}
\hline \multirow{2}{*}{$\begin{array}{l}\text { Year with } \\
\text { buffer }\end{array}$} & \multirow{2}{*}{$\begin{array}{c}\text { Overlapped } \\
\text { area }\end{array}$} & \multicolumn{11}{|c|}{ Buffer distance (m) } \\
\hline & & 0 & 1 & 2 & 3 & 4 & 5 & 6 & 7 & 8 & 9 & 10 \\
\hline \multirow{2}{*}{2001} & (ha) & 8.0 & 10.3 & 12.0 & 13.1 & 14.0 & 14.7 & 15.3 & 15.8 & 16.2 & 16.5 & 16.8 \\
\hline & $(\%)$ & 44.1 & 56.9 & 65.9 & 72.2 & 77.1 & 81.1 & 84.3 & 87.0 & 89.3 & 91.1 & 92.5 \\
\hline \multirow[t]{2}{*}{2011} & (ha) & 8.0 & 10.2 & 11.3 & 12.0 & 12.4 & 12.7 & 13.0 & 13.1 & 13.3 & 13.4 & 13.5 \\
\hline & $(\%)$ & 57.7 & 73.1 & 81.2 & 86.2 & 89.3 & 91.6 & 93.3 & 94.6 & 95.6 & 96.3 & 97.0 \\
\hline
\end{tabular}

Table 6

378 Overlapped root rot area in ha and percentage (\%) between two years if buffer zones are 379 created for one year for Field 2. 


\begin{tabular}{cccccccccccccc}
\hline \multirow{2}{*}{$\begin{array}{c}\text { Year with } \\
\text { buffer }\end{array}$} & $\begin{array}{c}\text { Overlapped } \\
\text { area }\end{array}$ & 0 & 1 & 2 & 3 & 4 & 5 & 6 & 7 & 8 & 9 & 10 \\
\cline { 3 - 12 } & (ha) & 5.1 & 5.5 & 5.8 & 6.1 & 6.3 & 6.5 & 6.7 & 6.8 & 6.9 & 7.0 & 7.1 \\
& (\%) & 65.1 & 70.5 & 74.5 & 77.7 & 80.5 & 82.9 & 85.0 & 86.8 & 88.3 & 89.6 & 90.9 \\
& (ha) & 5.1 & 6.2 & 7.0 & 7.7 & 8.2 & 8.6 & 8.9 & 9.2 & 9.5 & 9.8 & 10.0 \\
\hline \multirow{2}{*}{2012} & (\%) & 45.3 & 55.1 & 62.4 & 68.1 & 72.5 & 76.2 & 79.3 & 82.0 & 84.4 & 86.5 & 88.3
\end{tabular}

\section{Conclusions}

Results from this study demonstrate that cotton root rot tends to occur in the same general areas within fields in recurring years, even though variations in infection patterns exist over the years. The relative stability of cotton root rot-infected areas indicates that historical remote sensing imagery can be used for the site-specific management of the disease in the future years. Numerous unsupervised and supervised image classification methods can be applied to multispectral imagery for accurately differentiating infected areas from non-infected areas, but the NDVI-based ISODATA classification appears to be a simple and effective method for generating root rot infection maps.

To account for the potential expansion and temporal variation of the disease, buffer zones can be added around the infected areas in the original classification maps for generating 394 prescription maps. The selection of the optimal buffer distance depends on multiple factors such 395 as infection extent and pattern, availability of imagery for single season or multiple seasons, and 396 the producer's risk tolerance. For the two fields in this study, when the images from both years 397 were used to create merged classification maps, a buffer distance of $5 \mathrm{~m}$ would be appropriate. 398 When the image from one single year was used, a buffer distance of $10 \mathrm{~m}$ could be necessary. 399 Although arbitrary, a buffer distance of $3-12 \mathrm{~m}$ should be sufficient to accommodate the 
expansion and temporal variation of the disease. The procedures and results presented in this 401 paper provide general guidelines for the creation of prescription maps and have practical 402 implications for site-specific management of cotton root rot.

\section{Acknowledgements}

This project was partly funded by Cotton Incorporated at Cary, North Carolina. The authors wish 407 to thank Rene Davis of USDA-ARS at Weslaco, Texas, Lee Denham and Fred Gomez of 408 USDA-ARS at College Station, Texas for taking the imagery for this study. Thanks are also 409 extended to Randy Rachel and John Barrett of Corpus Christi, Texas for allowing us to use their 410 fields. Mention of trade names or commercial products in this article is solely for the purpose of 411 providing specific information and does not imply recommendation or endorsement by the U.S. 412 Department of Agriculture. USDA is an equal opportunity provider and employer.

\section{$414 \quad$ References}

416 Drake, D.R., Minzenmayer, R.R., Multer, W.L., Isakeit, T., Morgan, G.D., 2013. Evaluation of 417 farmer applications of Topguard (flutriafol) for cotton root rot control in the first Section 18 418 exemption year. In: Proc. Beltwide Cotton Conf. National Cotton Council of America, 419 Memphis, Tennessee, pp. 152-156.

420 Escobar, D.E., Everitt, J.H. Noriega, J.R. Davis, M.R., Cavazos, I., 1997. A true digital imaging 421 system for remote sensing applications. In: Proc. 16th Biennial Workshop on Color 422 Photography and Videography in Resource Assessment. American Society for 423 Photogrammetry and Remote Sensing, Bethesda, Maryland, pp. 470-484.

424 Ezekiel, W.N., Taubenhaus, J.J., 1934. Cotton crop losses from Phymatotrichum root rot. J. 425 Agric. Res. 49(9), 843-858. 
426 Intergraph Corporation, 2013. ERDAS Field Guide. Intergraph Corporation, Huntsville, Alabama.

427 Isakeit, T., Minzenmayer, R.R., Sansone, C.G., 2009. Flutriafol control of cotton root rot caused 428 by Phymatotrichopsis omnivora. In: Proc. Beltwide Cotton Conf. National Cotton Council of 429 America, Memphis, Tennessee, pp. 130-133.

430 Isakeit, T., Minzenmayer, R.R., Drake, D.R., Morgan, G.D., Mott, D.A., Fromme, D.D., Multer, 431 W.L., Jungman, M., Abrameit, A., 2012. Fungicide management of cotton root rot 432 (Phymatotrichopsis omnivora): 2011 results. In: Proc. Beltwide Cotton Conf. National Cotton 433 Council of America, Memphis, Tennessee, pp. 235-238.

434 Lyda, S.D., Burnett, E., 1970. Influence of benzimidazole fungicides on Phymatotrichum 435 omnivorum and Phymatotrichum root rot of cotton. Phytopathology 60, 726-728.

436 Nixon, P.R., Lyda, S.D., Heilman, M.D., Bowen, R.L., 1975. Incidence and control of cotton root 437 rot observed with color infrared photography. Pub. No. MP1241. Texas A\&M Agricultural $438 \quad$ Experiment Station, College Station, Texas.

439 Nixon, P.R., Escobar, D.E., Bowen, R.L., 1987. A multispectral false-color video imaging system 440 for remote sensing applications. In Proc. 11th Biennial Workshop on Color Aerial 441 Photography and Videography in the Plant Sciences and Related Fields. American Society 442 for Photogrammetry and Remote Sensing, Bethesda, Maryland, pp. 295-305, 340.

443 Pammel, L.H., 1888. Root Rot of Cotton, or "Cotton blight”. Texas Agric. Exp. Station Ann. Bull. $444 \quad 4,50-65$.

445 Percy, R.G., 1983. Potential range of Phymatotrichum omnivorum as determined by edaphic $446 \quad$ factors. Plant Dis. 67, 981-983.

447 Rush, C.M., Lyda, S.D., 1984. Evaluation of deep-chiseled anhydrous ammonia as a control for 448 Phymatotrichum root rot of cotton. Plant Dis. 68, 291-293.

449 Smith, H.E., Elliot, F.C., Bird, L.S., 1962. Root rot losses of cotton can be reduced. Pub. No. 450 MP361. Texas A\&M Agricultural Extension Service, College Station, Texas. 
451 Taubenhaus, J.J., Ezekiel, W.N., Neblette, C.B., 1929. Airplane photography in the study of 452 cotton root rot. Phytopathology 19, 1025-1029.

453 Uppalapati, S.R., Young, C.A., Marek, S.M., Mysore, K.S., 2010. Phymatotrichum (cotton) root 454 rot caused by Phymatotrichopsis omnivora: retrospects and prospects. Molecular Plant $455 \quad$ Pathol. 11(3), 325-334.

456 Whitson, R.S., Hine, R.B., 1986. Activity of propiconazole and other sterol-inhibiting fungicides 457 against Phymatotrichum omnivorum. Plant Disease 70, 130-133.

458 Yang, C., 2012. A high resolution airborne four-camera imaging system for agricultural 459 applications. Comput. Electron. Agric. 88, 13-24.

460 Yang, C., Fernandez, C.J., Everitt, J.H., 2005. Mapping Phymatotrichum root rot of cotton using 461 airborne three-band digital imagery. Trans. ASAE 48(4), 1619-1626.

462 Yang, C., Odvody, G.N., Fernandez, C.J., Landivar, J.A., Minzenmayer, R.R., Nichols, R.L., 463 2015. Evaluating unsupervised and supervised image classification methods for mapping $464 \quad$ cotton root rot. Precision Agric. 16, 201-215.

465 Yang, C., Odvody, G.N., Fernandez, C.J., Landivar, J.A., Minzenmayer, R.R., Nichols, R.L., 466 Thomasson, J.A., 2014. Monitoring cotton root rot progression within a growing season 467 using airborne multispectral imagery. J. Cotton Sci. 18(1), 85-93.

468 Yang, C., Westbrook, J.K., Suh, C.P., Martin, D.E., Hoffmann, W.C., Lan, Y., Fritz, B.K., 469 Goolsby, J.A., 2014. An airborne multispectral imaging system based on two consumer470 grade cameras for agricultural remote sensing. Remote Sens. 6, 5257-5278. 